\title{
Retraction Note: Calculation of forest soil erosion rate based on improved FEMD Algorithm and green economic development
}

\author{
Liuyi Dai ${ }^{1,2}$
}

Published online: 23 November 2021

(c) Saudi Society for Geosciences 2021

Retraction Note: Arabian Journal of Geosciences (2021) 14: 1054 https://doi.org/10.1007/s12517-021-07355-1

The Editor-in-Chief and the Publisher have retracted this article because the content of this article is nonsensical. The peer review process was not carried out in accordance with the Publisher's peer review policy. The author disagrees with this retraction.

The original article can be found online at https://doi.org/10.1007/ s12517-021-07355-1.

Liuyi Dai

liuyi.d@outlook.com

1 Department of Economics, Pusan National University, Busan 46241, Republic of Korea

2 Baotou Teachers' College, Inner Mongolia University of Science and Technology, Baotou 014010, Inner Mongolia, China 